\title{
Cristóbal Suárez de Figueroa, autor del segundo Quijote. Examen crítico de una postulación
}

\author{
John O’Kuinghttons Rodríguez
}

O’Kuinghttons Rodríguez, J. (2021). Cristóbal Suárez de Figueroa, autor del segundo Quijote.

Examen crítico de una postulación. Revista de Filología y Lingüística de la Universidad de Costa

Rica, 47(2), e46789. doi: https://doi.org/10.15517/rfl.v47i2.46789

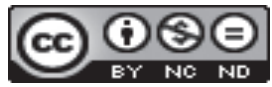

Doi: https://doi.org/10.15517/rfl.v47i2.46789

URL: https://revistas.ucr.ac.cr/index.php/filyling/index 
Revista de Filología y Lingüística de la Universidad de Costa Rica

ISSN: 0377-628X

ISSN: 2215-2628

filyling@gmail.com

Universidad de Costa Rica

Costa Rica

\section{Cristóbal Suárez de Figueroa, autor del segundo Quijote. Examen crítico de una postulación}

OKKuinghttons Rodríguez, John

Cristóbal Suárez de Figueroa, autor del segundo Quijote. Examen crítico de una postulación

Revista de Filología y Lingüística de la Universidad de Costa Rica, vol. 47, núm. 2, e46789, 2021

Universidad de Costa Rica, Costa Rica

Disponible en: http://www.redalyc.org/articulo.oa?id=33266553010

DOI: https://doi.org/10.15517/rfl.v47i2.46789

\section{(c) $(1) \Theta \Theta$}

Esta obra está bajo una Licencia Creative Commons Atribución-NoComercial-SinDerivar 3.0 Internacional. 


\title{
Cristóbal Suárez de Figueroa, autor del segundo Quijote. Examen crítico de una postulación
}

\section{Cristóbal Suárez de Figueroa, Author of The Second Quixote. A Critical Analysis of a Candidacy}

John O'Kuinghttons Rodríguez

Universidad de São Paulo, São Paulo, Brasil

johnochile@gmail.com

(iD) https://orcid.org/0000-0002-2815-3987

\author{
DOI: https://doi.org/10.15517/rfl.v47i2.46789 \\ Redalyc: http://www.redalyc.org/articulo.oa?id=33266553010
}

Recepción: 20 Julio 2020

Aprobación: 01 Septiembre 2020

\section{Resumen:}

Nuestro objetivo es revisar de manera crítica la postulación de Cristóbal Suárez de Figueroa como probable autor del Quijote de Alonso Fernández de Avellaneda. Para ello cotejaremos los argumentos vindicativos de sus dos principales motivadores, a saber, Enrique Espín y Enrique Suárez Figaredo, remitiéndonos específicamente a los textos en que se defiende dicha candidatura. Comenzaremos con una generalidad de lo que hasta ahora conocemos de Avellaneda para luego concentrarnos en el germen y desarrollo de la candidatura de Figueroa. Concluiremos con una reflexión sobre el conocimiento del ámbito artístico de la época áurea que se puede alcanzar a partir del escrutinio de posibles candidatos de la imitación emprendida por Avellaneda, tomando como ejemplo la postulación de Suárez Figueroa. Asimismo, en ciertos momentos de nuestro estudio nos remitiremos al estado actual de los métodos de búsqueda de autoría de la novela.

Palabras Clave: siglos áureos, Avellaneda, Cervantes, Figueroa, autoría.

\begin{abstract}
:
This article aims at making a critical review of the candidacy of Cristóbal Suárez de Figueroa as one of the possible authors of Avellaneda's Quixote. To accomplish this goal, we will compare the arguments presented by Enrique Espín and Enrique Suárez Figaredo, the most important advocates of this candidature, focusing specifically on the texts that defend this candidacy. Firstly, we will give an overview of what we know about Avellaneda. Secondly, we will concentrate on the origin and development of Figueroa's candidacy. Finally, we will reflect on how the research about Avellaneda's identity can guide us on the knowledge of the Golden Age's artistic context, when we take the name of Suárez Figueroa as the starting point of the study. To develop this study, we will also refer to the state of the research methods on the field of authorship attribution as far as Avellaneda's Quixote is concerned
\end{abstract}

KEYWORDS: Golden age, Avellaneda, Cervantes, Figueroa, authorship.

\section{INTRODUCCIÓN}

Hoy en día se tiende a vindicar el segundo Quijote como una novela no exenta de méritos, entendiendo que, aun cuando en su lectura gravite inevitable la estatura de su antecesor, comporta trazos propios que no conviene subestimar. Para valorarla debemos señalar, primero, que, mientras en el Quijote cervantino repercute un programa literario, en el de Avellaneda resuena uno moral. Lo segundo es que, si bien Cervantes usó la locura como tema para su parodia, Avellaneda, solícito al fin didáctico inculcado por la tradición aristotélica, aprovechó la insania del personaje central para advertir que de un loco nada se aprende. Esta enseñanza, claro está, no era advenediza, pues se afirma en corrientes de pensamiento político y social bien conocidos en la época. A estas dos variables hay que añadir una de orden narrativo: los personajes tomados por Avellaneda difieren de los ideados por su mentor debido a su profunda linealidad ideológica ${ }^{1}$. La vindicación que mencionamos al inicio no posterga ni deslegitima el interés por develar la identidad de Avellaneda. El examen de los pros y contras que validan, refuerzan, debilitan o refutan tales o cuales candidaturas remunera 
a su estudioso con el conocimiento articulado y diverso de textos y autores que de otro modo podrían quedar desatendidos.

Debemos, pues, destacar a priori que nuestro propósito filológico no es ni ha sido en momento alguno desensombrecer la identidad de Avellaneda, sino aquilatar los méritos de una candidatura de consistentes argumentaciones a favor, para así conocer los trazos estilísticos y sociales de un autor actualmente poco solicitado.

\section{Lo Que Sabemos de Avellaneda}

Desde el siglo XVIII se han venido aplicando y consagrando distintos métodos para elucidar la identidad de Avellaneda $^{2}$. Tres han sido los medios que con resultados diversos han permitido la valoración o refutación de candidaturas: estudio de biografías y contexto socio literario; examen de anagramas; escrutinio de índices formales ${ }^{3}$.

Las aproximaciones biográficas y de situación histórica han permitido ordenar ciertos requisitos que hoy por hoy han ganado cierto consenso. Osterc, por ejemplo, señala un perfil que contiene cuatro rasgos dentro de lo que denomina "los modestos resultados" a que ha llegado la crítica:

1. Avellaneda no pertenecía a los literatos de alto rango, pero sí gozaba del apoyo de personas muy influyentes en el mundo oficial.

2. Era, si no amigo íntimo, a buen seguro un gran admirador de Lope de Vega.

3. Si bien quizá no pertenecía a la Orden de Santo Domingo, era muy instruido en teología y profesaba gran devoción por el rosario, devoción propia de los dominicos.

4. Conocía tan bien Zaragoza y una amplia zona de Aragón, y en su lenguaje hay tan claras singularidades lingüísticas aragonesas, que sin duda alguna fue un aragonés, como lo afirmó Cervantes (citado por Riquer, 2003, p. 472).

A estos trazos iniciales, Suárez Figaredo agrega dos tipos de variables. Las primeras las identifica como seguras, y son:

1. Avellaneda es bastante más joven que Cervantes.

2. Avellaneda siente verdadera antipatía por Cervantes.

3. Avellaneda está al corriente de noticias, batallitas y rumores injuriosos entre literatos de la Corte.

4. Avellaneda tiene una sólida formación.

5. Avellaneda tiene juicio crítico: no resta mérito a otras obras de Cervantes, y juzga que en DQ-I no sacó todo el partido posible a sus principales personajes.

6. Avellaneda, por venganza personal, o por demostrarse algo a sí mismo, decide escribir su propio Quijote; y elige el momento en que más daño económico puede causar a Cervantes, y moral, pues los lectores podrán hacer comparaciones.

7. Avellaneda se vería obligado a apartarse de su registro como escritor por no ser de su invención el tema principal ni la caracterización de los personajes (que, además, exagera para, en su opinión, mejorarlos). (Suárez Figaredo, 2004, p. 95).

A continuación, el autor agrega las menos incuestionables:

De los Preliminares de DQA:

a) Avellaneda dispone de medios económicos para financiar la edición de su DQA, quizá aportados “a fondo perdido" por un tercero.

b) Avellaneda es admirador de Lope de Vega, si ya no amigo. 
c) Avellaneda, en lo personal, se siente ofendido por Cervantes, que le habría aludido en DQ-I.

d) Avellaneda podía ser reconocido por el empleo de algún seudónimo y, quizá, otros detalles ${ }^{4}$.

e) Avellaneda, sabiendo bien Cervantes a quién habría aludido en DQ-I, no tuvo reparo en descubrírsele en el prólogo de DQA (Suárez Figaredo, 2004, p. 95).

Para complementar estos rasgos, Javier Blasco aporta otros igualmente significativos:

[Avellaneda] es dueño de una cultura considerable, con notable dominio de las fuentes bíblicas y clásicas popularizadas por los studia humanitatis y con un buen conocimiento de la literatura (de los textos y de los entresijos civiles) del momento; ideológicamente parece evidente su adscripción al espíritu de la contrarreforma, con una clara toma de partido en el debate teológico sobre el debate "de auxiliis" que, en 1607, enfrenta a jesuitas y dominicos; se trata de una persona muy interesada en el orden social y político establecido (mientras que Cervantes sitúa al lector en la perspectiva de don Quijote y de Sancho, Avellaneda ve el mundo desde la altura de las clases sociales privilegiadas vinculada a ciertos sectores de la nobleza); toma partido (aunque con precaución) en relación con el tema de la expulsión de los moriscos; demuestra también un buen conocimiento de tres ambientes: el de la vida estudiantil universitaria, el de la fiesta (las mascaradas cortesanas y urbanas), y el de la vida conventual; es un hombre que conoce bien a Cervantes y que siente una gran admiración por Lope, con quien sintoniza ideológica y socialmente; y, finalmente, tiene una buena razón para ocultar su verdadera identidad (Blasco, s. f., pp. 7-8).

\section{SuÁrez de Figueroa: historia de UNA POSTUlación}

En 1990 apareció en Murgetana un artículo firmado por el padre Florencio Álvarez Díez en donde resumía con amistoso tenor la contribución de Enrique Espín Rodrigo para develar la autoría de la novela que nos ocupa. Las notas de Espín -cuyo padre, Joaquín Espín Rael barruntó por años la candidatura de Francisco de Quevedo- vieron luz gracias al esfuerzo de Matilde E. Navarro Martínez y doña Carmen Ayala, su viuda, que financió la publicación. La aportación de la cual hablamos fue la propuesta del escritor vallisoletano Cristóbal Suárez de Figueroa como legítimo Avellaneda, que posteriormente contó con la adhesión de un casi homónimo, el ingeniero y profundo conocedor de las creaciones áureas Enrique Suárez Figaredo, quien reconoce haber leído el artículo del padre Álvarez después de formalizar su proposición.

Los otros aportes de Espín citados por Álvarez son las atribuciones al mismo Suárez de Figueroa de El Buscón y La Tía Fingida, que fue incorporada a las Novelas ejemplares desde su hallazgo en el siglo XVIII en un manuscrito junto a versiones de El celoso extremeño y Rinconete y Cortadillo.

\subsection{Sobre la supuesta ofensa}

Según Espín, luego replicado y comentado por Álvarez, Figueroa debió emprender su Quijote por una supuesta ofensa de Cervantes contenida en el capítulo VI de la primera parte, que narra el donoso escrutinio de la biblioteca del manchego. Entre otras muchas cosas, Cervantes hace que sus personajes evalúen con criterios estéticos y morales no solo los títulos con que se deparan sino el oficio de la traducción, ejercicio que trajo los principales reconocimientos en vida al candidato. A propósito de Ludovico Ariosto el cura señala: "al cual, si aquí le hallo, y que habla en otra lengua que la suya, no le guardaré respeto alguno; pero si habla en su idioma, le pondré sobre mi cabeza” (Cervantes, 2005, p. 57), a lo que luego agregará:

[...] le quitó mucho [al libro original] de su natural valor, y lo mesmo harán todos aquellos que los libros de verso quisieran volver en otra lengua: que por mucho cuidado que pongan y habilidad que muestren, jamás llegarán al punto que ellos tienen en su primer nacimiento (Cervantes, 2005, p. 57).

Los autores sostienen que por gracia de estas breves aserciones, Cervantes se ganó la antipatía de Figueroa, pues tiempo antes había traducido en verso El pastor Fido, a partir de Guarini ${ }^{5}$. Figueroa publicó una mejorada segunda traducción en 1609 que, no obstante, contó con el elogio del propio Cervantes en II-LXII: 
Y no por esto quiero inferir que no sea loable este ejercicio del traducir; porque en otras cosas peores se podría ocupar el hombre, y que menos provecho le trujesen. Fuera desta cuenta van los dos famosos traductores: el uno, el doctor Cristóbal de Figueroa, en su pastor Fido, y el otro, don Juan de Jáurigui, en su Aminta, donde felizmente ponen en duda cuál es la traducción o cuál el original (Cervantes, 2005, pp. 832-833).

Esta amistosa mención, afirma Suárez Figaredo, debió ser una suerte de pacto concebido por Cervantes para pacificar las relaciones ${ }^{6}$, lo cual sustentaría la idea de que el alcalaíno no desconoció la identidad de su rival. Conforme Espín, es posible que la animadversión de Figueroa hacia Cervantes se hubiese incrementado por la protección que Pedro Fernández de Castro, VII conde de Lemos, le negó a él y concedió a su colega ${ }^{7}$. El primer ajuste de cuentas -afirma Espín- lo propinó en Plaza Universal de todas ciencias y artes, adaptación del texto de Tomasso Garzoni Piazza universale, en el que rebajaba a inmorales las novelas de Cervantes, que, según hace constar, las empleaban los alcahuetas para seducir a las jóvenes. Asimismo, critica la novelización de experiencias personales como El amante liberal y El capitán cautivo, la dedicatoria al conde de Lemos que preside Los trabajos de Persiles y Segismunda, y se burla de la mala fortuna que corrieron las representaciones de las Ocho comedias ${ }^{8}$.

Tanto biógrafos como filólogos han redundado en un retrato ríspido de Figueroa. Las fuentes lo tratan de quisquilloso, malhumorado, renuente y dominado por el rencor y la envidia ${ }^{9}$. Al respecto, hay que sopesar que una atribución de autoría sustentada únicamente en la incidencia de ofensas contra Cervantes puede ser apresurada. Recordemos, por ejemplo, que en su prólogo Avellaneda acusa a Cervantes de ser "mal contentadizo" y que Figueroa recurre en Elpasajero (Suárez de Figueroa, 2018) ${ }^{10}$ tres veces al mismo calificativo ${ }^{11}$. No obstante, las burlas y pullas de este autor se extendieron, por lo demás, a otros autores, obras y hasta géneros. Son célebres los dicterios que dirigió contra Juan Ruiz de Alarcón, a quien le censuró no solo su arribismo por añadir el don a su nombre sino que también se rió de su deformación física ${ }^{12}$. Aun cuando estas agresiones le granjearon la distancia de sus contemporáneos y el olvido de sus obras, no llegaron a lesionar íntegramente su prestigio ${ }^{13}$. Sobre esto reflexiona Espín:

Su vida no se vio favorecida por la fortuna, aunque perseveró insistentemente, rechazando cualquier procedimiento indigno para alcanzar el triunfo. No puede ser calificado entre los más grandes escritores, pero sí debemos reconocerle ser hombre de profundos principios morales y defensor de los más altos ideales literarios y políticos (Espín, 1993, pp. 64-65).

\subsection{Los argumentos de Enrique Espín}

Enrique Espín (1993) sostuvo su atribución de autoría sobre unas variables que podrían reducirse a dos grandes ejes: coincidencias temáticas y de estilo; rasgos lexicales. El primero puede desglosarse del siguiente modo:

- Condena del ocio: reprobación de la ociosidad femenina; recomendación de lecturas piadosas para los ratos de descanso.

- Identificación equivocada del goloso con el epicúreo.

- Crítica a la gula (sobre todo en la mujer).

- La calificación de borrachos a los flamencos.

- Crítica a la maledicencia (sobre todo en la mujer).

- Crítica a la envidia.

- Crítica a la vida licenciosa en la mujer.

- Diatribas contra profesiones y oficios, como médicos, mercaderes y venteros.

- Valoración de la educación de los hijos: disciplina y estudio (evidencia del trasfondo pedagógico de la Ratio studiorum).

- Defensa de la institución matrimonial. 
- Incredulidad por la quiromancia.

- Alusión a la conquista de Chipre.

- Episodios escatológicos.

- Figuración de la crueldad.

- Coincidencias entre personajes como Japelín y Juan Fernández (el pícaro ventero de El Pasajero [Suárez de Figueroa, 2018]).

En cuanto al segundo, Espín se socorre de la clasificación de léxico conforme la terminología de Bernard Pottier, lo que redunda en la identificación de palabras simples, palabras derivadas, lexía compleja (sintagmas) y lexía textual (locuciones o frases proverbiales). Al cotejar su trabajo con el de este investigador, Suárez Figaredo apunta las debilidades de que, a su juicio, adolece el estudio de su colega, entre estas, la restricción al análisis de únicamente ciertas formas sintagmáticas distribuidas en distintas obras de Figueroa como el descuido del guiño "ofender a mí" ${ }^{14}$ o la marginación de la llamativa secuencia artículo + preposición + que.

\subsection{La fecha de composición}

A diferencia de Martín Jiménez ${ }^{15}$, Espín sitúa como probable datación de composición del segundo Quijote el período comprendido entre 1606 y 1609 , vale decir, antes de que se decidiera la expulsión de los moriscos. Afirma su hipótesis en evidencias como el modo, ora burlesco ora ponderativo, con que Avellaneda se refiere a estos. Supone, asimismo, que el prólogo debió escribirse en 1614, el mismo año de la publicación, y que para "acomodar la novela a la reciente expulsión de los moriscos (1609-1610) ${ }^{16}$ y actualizarla en lo posible" (Espín, 1993, p. 20), añadió el comentario de las líneas iniciales sobre los moros agarenos. Sostiene también que dicho párrafo revela una enmienda forzada al hilar el origen de Alisolán con la inmediata contextualización del hidalgo. Es de extrañar, mantiene Espín, que a lo largo de la novela no se haga mención alguna al proceso de expulsión, y que en su defecto se hable con tono elogioso de los expulsados, como el pasaje que dibuja de don Álvaro Tarfe:

[...] descendía del antiguo linaje de los moros Tarfes de Granada, deudos cercanos de sus reyes y valerosos por sus personas, como se lee en las historias de los reyes de aquel reino, de los Abencerrajes, Zegríes, Gomeles y Mazas, que fueron cristianos después que el católico rey Fernando ganó la insigne ciudad de Granada (Fernández de Avellaneda, 2005, p. 19).

Luego refuerza su dictamen aludiendo a la amenaza que hace un autor de compañía a Sancho para que se convierta en moro, según consta en el capítulo XXVI. Al respecto señala:

La broma del autor de comedias de volver moro a Sancho Panza tiene su gracia y es oportuna porque responde a una realidad de la época, la existencia de moros y moriscos en España. De otra forma la chanza carecería de interés (Espín, 1993, p. 22).

Los otros datos que reporta Espín para fijar el posible marco de redacción de la novela son:

- Referencias en el Quijote de Avellaneda a amantes de Lope de Vega con las que mantuvo relaciones antes de 1609 (como se constata en el capítulo II) (Espín, 1993, p. 32).

- Proximidad cronológica de la conquista de Ostende, que tuvo lugar el 20 de septiembre de 1604 (como se constata en el capítulo XIV) (Espín, 1993, p. 32).

- La corte estaba de nuevo asentada en Madrid, hecho que se produjo en 1606 (como se constata en el capítulo XIII) (Espín, 1993, p. 33).

- Sancho cita unos "reales de a ocho", cuya acuñación se produjo a partir de 1607 (como se constata en el capítulo III) (Espín, 1993, p. 34).

- Ninguna alusión a lo ordenado en las Pragmáticas publicadas el 3 de enero de 1611 (Espín, 1993, p. 35) ${ }^{17}$. 
Los juicios de Espín dan sustento a la idea de que la segunda parte cervantina fue escrita de forma lineal. Suárez Figaredo desestima este dictamen y se pregunta que, si el objetivo de Cervantes fue desautorizar a Avellaneda, ¿por qué habría de esperar hasta II-LIX para enfrentarlo ${ }^{18}$ No obstante, para este autor la obra rival debió llegar a manos de Cervantes mucho antes de lo que el registro de II-LIX permite colegir. Para ello recurre a la datación precisa de la carta de Sancho:

[...] el libro debió caer en las manos de Cervantes en el verano de 1614, si atendemos a la fecha de la carta de Sancho a su esposa: "Deste castillo [de los Duques] a veynte de Iulio 1614" (cap. ii-xxxvi). Este es el momento en que Cervantes modifica drásticamente la cronología del relato, iniciado "casi un mes" después de finalizada la primera parte. Sagazmente observó Martín de Riquer: "Ahora sí que el lector atento observa que toda la cronología de la narración se ha desmoronado... La continuación apócrifa obligó a Cervantes a cambiar el itinerario de don Quijote y Sancho: no se encaminarán a Zaragoza, como había trazado mucho antes y, de acuerdo con ello, hizo Avellaneda, sino a Barcelona... Cervantes insertó la fecha del 20 de julio de 1614 porque, habiendo aparecido aquel mes el Quijote de Avellaneda, tenía el propósito de referirse indignamente a él" (Suárez Figaredo, 2009, pp. 26-27).

Asimismo, toma en cuenta no solo lo que menciona Cervantes sino también lo que omite, como, por ejemplo, toda referencia a la obra rival en el prólogo de las Novelas ejemplares. Por ello sería comprensible que hacia el 14 de julio de 1613 Cervantes no conociera bajo forma impresa ni manuscrita la existencia de la imitación. La evidencia de su conocimiento manifiesto solo se registra en julio de 1615, según consta en el privilegio de las Ocho comedias. Adjunto a estas dataciones, Suárez Figaredo pone en liza un nuevo eje temporal. Señala que el segundo Quijote parece haber sido compuesto con fluidez, sin baches significativos a excepción de algún descuido menor, como el conocido segmento "Después de haber sido llevado don Quijote por el cura y el barbero y la hermosa Dorotea a su lugar en una jaula, con Sancho Panza, su escudero" (Fernández de Avellaneda, 2005, p. 208), en el que Avellaneda parece olvidar que Dorotea dejó al caballero en la venta de Juan Palomeque y no en su lugar. Ello puede ser muestra, sigue el autor, de que el imitador no tenía demasiado fresca la novela que quiso continuar, por lo que probablemente su redacción se inició en 1612 o 1613, tiempo en que debió enterarse por las noticias contenidas en las Novelas ejemplares que Cervantes escribía la segunda parte de su novela. Este período lo reforzaría la alusión en el prólogo de 1614 a la novela de Salas Barbadillo La hija de la Celestina, que se publicó en $1612^{19}$.

\subsection{Ningún sinónomo para Suárez Figueroa}

Al tenor de sus estudios, Suárez Figaredo reconoce que no ha logrado localizar en el Quijote de 1605 un nombre que remita directa u oblicuamente a Cristóbal Suárez de Figueroa. A pesar de ello, la búsqueda de un sinónomo iluminador lo ha conducido hasta el poeta y guitarrista Vicente Espinel, creador de la décima, autor de la novela picaresca Relaciones de la vida del escudero Marcos de Obregón, coetáneo de Cervantes y dueño de una vida militar poblada de incógnitas. La alusión a este autor, sostiene Figaredo, se origina en el penúltimo capítulo de DQ-I, donde figura la imprevista historia de un cabrero que narra la desventura de una joven a manos un soldado. Juzgando que la inclusión del relato no parece pertinente para el final de la primera parte, Figaredo arguye que dicho episodio abriga una intención alterna. Orientado por esta sospecha, arribó al nombre de Vicente de la Rosa, burlador de Leandra, que guarda notorias afinidades con la hoja de vida de Espinel ${ }^{20}$. No obstante, esta temprana suposición, que no prosperó, entrampa, como la de Salas, en el dato extra literario, pues Espinel y Cervantes no conocieron la mutua antipatía, sino todo lo contrario. Tanto Lope de Vega, que fue su discípulo, como Cervantes, le profesaban admiración, lo cual anula el móvil de animadversión que debió condicionar a Avellaneda ${ }^{21}$. 


\subsection{Conclusiones de Suárez Figaredo}

A juicio de Suárez Figaredo (2004), la lectura tradicional que se ha hecho del prólogo de 1614, vale decir, su comprensión como texto unívoco y rectilíneo, ha impedido interpretar sus modulaciones irónicas. Asimismo, dado que tradicionalmente se ha prestado excesiva importancia a los guiños dejados por Cervantes -huellas aragonesas, clericales, sinónimos y otros detalles- ha pasado inadvertido por tanto tiempo el nombre de Cristóbal Suárez de Figueroa. Sostiene que los datos proporcionados por el cotejo lexical, las indagaciones biográficas (que perfilan a Figueroa como hombre propenso a las apropiaciones y enemistado con Cervantes) y filológicas han robustecido su postulación, al punto de que aun investigadores como Alfredo Rodríguez López-Vásquez (Fernández de Avellaneda, 2011), que han dado credenciales a otro escritor, han aceptado la altísima probabilidad de autoría que le es atribuible a Suárez de Figueroa. Según sus propias palabras, los textos de Figueroa guardan muchas más afinidades formales con el segundo Quijote que los de todos los escritores atendidos hasta el momento.

Los argumentos estrictamente biográficos que lo llevan a ponderar la postulación de Figueroa se resumen así:

[...] la estancia de Sancho en la cárcel y el relato de sus cuitas tienen un correlato en la estancia de Figueroa en la cárcel de Cuéllar; la idealizada amada granadina de Álvaro Tarfe coincide también con el amor trágico de Figueroa por una noble dama granadina; la evidencia de italianismos y latinismos concuerdan con su larga estancia y estudios en Italia; y la anécdota que ha desvelado Javier Blasco sobre el episodio de la cátedra de Alcalá como trasunto de una de Valladolid, se ajusta a la formación y vivencias vallisoletanas del Doctor Figueroa. Pero todos estos elementos no pueden usarse como criterios de atribución; las bases de esta atribución son objetivas y se apoyan en la comprobación de frecuencias léxicas y el cotejo con los de más autores propuestos a partir de un corpus amplio y de un segundo corpus de referendo (Fernández de Avellaneda, 2011, pp. 69-70).

Un aspecto que importa hacer constar y que debiera remarcarse en cualquier indagación de la autoría, es el peso distintivo que los comportamientos éticos asumen en determinadas candidaturas y en otras no. Prueba de esta propensión es la insistencia con que se aplican medidas morales a Figueroa y se omiten cuando se trata de autores como Quevedo, Cervantes o Lope de Vega. A pie de esta crítica, Rodríguez ${ }^{22}$ advierte sobre las consecuencias epistemológicas que resultan de la falta de rigor en los criterios selectivos y evaluativos que definen una postulación.

\section{REFLEXIONES FINALES. El CONOCIMIENTO DE LOS SIGLOS ÁUREOS}

Hacia 1621, un anónimo y satírico redactor concibió una biblioteca compuesta no por trabajos ejemplares sino por lo que llamó una "infame mercadería". El texto se conoce como Carta ridícula de Diego Mofar y en una de sus páginas se habla de un río al que se han arrojado por ruindad elemental memoriales pro genoveses y contra Barcelona, una historia de los condes de la misma ciudad compuesta por Fr. Berrellas, pronósticos para el año 1622, la Constitución de los impúberes, una traducción de Comentarios de César y una segunda parte de Don Quijote, escrita no por Miguel de Cervantes sino por un tordesillero de quien no provee el nombre. Habían transcurrido nada más que siete años de la publicación de la novela imitativa. Desde esta inmejorable evidencia de recepción mucho se ha dicho, valorado y contravalorado del texto de Avellaneda. Una de las tareas que ha impuesto el seudónimo premeditado por su autor ha sido, precisamente, rastrear sus huellas verídicas. Siguiendo trazos se han indagado vidas, opúsculos y obras mayores, amistades y tensiones personales, poéticas, claves retóricas y estilos, se han desempolvado memorias y resucitado autores, todo ello recurriendo a métodos que se esfuerzan por vindicar objetividad. Hemos sabido de las dinámicas articulaciones que es capaz de promover el afán de los anagramas, cuya sola mención hoy se nos figura como un pasatiempo invernal más que un canal de escrutinio. Hemos deparado con continuos escarceos en vidas de autores, en sus pasiones, viajes, oficios, amistades, recelos, amores e infortunios, y en una 
miríada de conjeturas, sospechas, fundadas o advenedizas. Hemos sabido de la suspicacia que despiertan las redundancias, los vocablos y sintagmas de apariencia unívoca, las huellas de lecturas y el oficio que se convierte en estilo.

Todas estas son consecuencias que desde antiguo ha concitado la identidad de un autor que apostó por referir no la sabiduría parcial del mayor héroe de la literatura hispana, sino su estricta enajenación. Cabe, pues, preguntarse: tras tantos desvelos, ¿nos hemos acercado al legítimo nombre de Avellaneda? Algunos académicos lo dan por sentado. Muchos se resignan a su imposibilidad. Otros declaran con el beneficio de la prudencia que hasta que no surja un documento conclusivo todo devendrá a conjetura. Quienes se han abocado a la tarea de desencubrimiento han seguido ciertas pistas que se extraen de la propia novela imitativa y del mismísimo Cervantes. Mientras aún se cuestiona si Avellaneda fue aragonés, clérigo o uno de los particpantes del círculo de Lope, no restan dudas de que fue un escritor de oficio, defensor del poder institucional y que conocía con acento la literatura de su época.

Al inicio de este trabajo advertimos que nuestra motivación no ha sido determinar una autoría sino revisar los pormenores de una candidatura y mostrar el conocimiento de los meandros literarios áureos a que se puede aspirar mediante el estudio de atribuciones de diversa procedencia. Como afirma J. P. Wickersham Crawford (2005) en su extensa biografía de Figueroa, hoy por hoy nuestro autor ha sido injustamente olvidado. Con ello, y a pesar de ello, vale destacar que ha sido precisamente el enigma de Avellaneda el impulso que ha revitalizado su nombre. Si convenimos en que la búsqueda de Avellaneda es uno de los muchos puntos de arranque que permiten organizar el estudio de los siglos áureos desde un eje ordenador, el examen de Figueroa bajo el cribo léxico, poético o histórico-social cobra una relevante unidad, dado que habrán de aplicársele claves consensuadas como la cercanía a Lope, el vínculo con la iglesia y la monarquía, el aragonesismo, entre otros. Estos factores operan como requisitos que el investigador de autoría debe atender como ejercicio formalizador ${ }^{23}$. Las directrices de búsqueda tienden a asentarse y a consolidar, gracias a los adelantos informáticos, las indagaciones estilográficas y tipográficas. Queda, pues, la certeza de que un investigador que proponga un nombre habrá de adentrarse con hondura en las vidas de su candidato y de Cervantes, en las poéticas y retóricas, en la historia de España, en los conventilleos de escritores, en obras y obrillas, en textos conocidos y textos por conocer. Otra cosa es si el autor efectivamente atiende o incumple aquellas directrices. Sean cuales sean sus resultados, el investigador habrá conocido, y dado a conocer, no solo un autor quizás preterido, sino un cuerpo de obras, de meridianos sociales, históricos, poéticos que de otro podrían quedar inobservados.

Dicho lo anterior, la postulación de Cristóbal Suárez de Figueroa es probablemente la que ha ganado mayores consensos. Las detracciones son mínimas y sus evidencias ingentes. Al escudriñar en su vida recuperamos a un autor cuyo temple pendenciero le granjeó no pocas enemistades. Sabemos, por ejemplo, que tras apuñalar a un caballero en Valladolid debió esconderse de la justicia viajando por el sur de España. Gracias a su revitalización comprobamos que en sus obras mayores fue cambiante respecto a Cervantes. Si en Plaza universal lo eleva, en El Pasajero (Suárez de Figueroa, 2018) hace precisamente lo contrario. Esta obra, concebida como un extenso diálogo de disquisiciones entre un maestro en artes y teología, un militar, un orífice y un doctor, se detiene en temas tan diversos como lo son las comedias, el gobierno, la vida estudiantil o las costumbres. Y entre sus múltiples divagaciones se suscitan dos actitudes que alientan una primera sospecha de autoría: el desdén hacia Cervantes ${ }^{24}$ y una apología al empleo de materiales literarios ajenos para la confección de obras propias.

Otros datos que constatamos en Figueroa es que conoció bien Italia y manejó con soltura la literatura de su tiempo (Avellaneda, recordemos, cumple con ambas habilidades). Asimismo, estudió derecho civil y canónico en Bolonia y se doctoró en Pavía. Ejerció de fiscal de Martesana y fue jurista en Nápoles. Aunque sus contemporáneos lo tildaron de orgulloso y arribista, contó con el mecenazgo de Juan Andrés Hurtado de Mendoza, de quien escribió una biografía. La eventualidad de autoría, enciende en Figueroa la interrogante de su cercanía a Lope y su pléyade. Según investigadores como Riquer (2003) y Suárez Figaredo (2004), nuestro 
autor admiraba al Fénix y debió tener algún grado de familiaridad con su círculo. Lo que resulta cuestionable es que, aun cuando es probable que haya amistado con el grupo, no fue completamente afín a sus preceptivas poéticas. En 1617 apareció un opúsculo, actualmente perdido, llamado La Spongia, firmado por el profesor de gramática de la Universidad de Alcalá, Pedro Torres Rámila, en el que se censuraban ciertas obras de Lope. Se ha propuesto que su coautor pudo ser el propio Figueroa. Según se colige de un fragmento de El Pasajero (Suárez de Figueroa, 2018), su discrepancia mayor con aquel debió ser la subversión de la unidad de acción. Suárez Figaredo sostenía que "cualquier poema puede tener cantidad de episodios; mas conviene sea una sola la cosa de que trate” (2004, p. 142). No obstante, este reparo no es necesariamente decisivo para medir su adherencia o desapego de la poética lopista. Pensemos, por ejemplo, y a modo de final, en que un autor tan ligado al círculo como Elisio de Medinilla vindicó con prudentes modulaciones la acción aristotélica ${ }^{25}$.

\section{BibLIOgRAFÍA}

Álvarez Díez, F. (1990). “El Quijote apócrifo” obra de Cristóbal Suárez de Figueroa. Murgetana, (81), 23-42.

Blasco, J. (s. f.). Avellaneda, secular enigma cervantino. Recuperado de http://uvadoc.uva.es/handle/10324/2432

Brioso Santos, H. (2007). Cristóbal Suárez de Figueroa: un enemigo de América y de los indianos en la España del siglo XVII. Anuario de Estudios Americanos, 64(1), 209-220. Recuperado de https://www.researchgate.net/publication/50284523_Cristobal_Suarez_de_Figueroa_un_enemigo_de_A merica_y_de_los_indianos_en_la_Espana_del_XVII

Cervantes, M. (1943). Obras completas. Madrid: Aguilar.

Cervantes, M. (2005). El Ingenioso Hidalgo Don Quijote de La Mancha. Ciudad de México: Grupo editorial Tomo.

Ehrlicher, H. (2016). La artificiosidad aumentada. Avellaneda como catalizador de la narrativa del Quijote. Recuperado de https://opus.bibliothek.uni-augsburg.de/opus4/frontdoor/deliver/index/docId/3704/file/Mesa_Redonda _Neue_Folge_33.pdf

Espín, E. (1993). El Quijote de Avellaneda fue obra del doctor Christoval Svarez de Figueroa. Recuperado de https://b ooks.google.es/books?id=mqVuzos-BjQC\&pg=PA8\&focus=viewport\&hl=pt-BR\#v=onepage\&q\&f=false

Fernández de Avellaneda, A. (2005). El Quijote apócrifo. Madrid: Biblioteca Nueva.

Fernández de Avellaneda, A. (2011). El Quijote apócrifo. Madrid: Cátedra.

Fernández de Avellaneda, A. (2014). Segundo tomo del ingenioso hidalgo don Quijote de la Mancha. Valladolid: Real Academia Española.

Hinrichs, W. (2016). Los felices continuadores de Avellaneda: expansión del mundo quijotesco después de 1614. Recuperado de https://opus.bibliothek.uni-augsburg.de/opus4/frontdoor/deliver/index/docId/3704/file/Me sa_Redonda_Neue_Folge_33.pdf

Iffland, J. (1999). De fiestas y aguafiestas: risa, locura e ideología en Cervantes y Avellaneda. Madrid: Iberoamericana.

Martín Jiménez, A. (2005). Cervantes y Pasamonte. La réplica cervantina al Quijote de Avellaneda. Madrid: Biblioteca Nueva.

Martín Morán, J. M. (2016). El diálogo en las dos segundas partes del Quijote. Recuperado de https://opus.bibliothek. uni-augsburg.de/opus4/frontdoor/deliver/index/docId/3704/file/Mesa_Redonda_Neue_Folge_33.pdf

O'Kuinghttons, J. (2015). Intersticios ideológicos en los Quijotes de Cervantes, Avellaneda y Montalvo: un estudio comparativo sobre las representaciones sociales dominantes en las obras. (Tesis doctoral). Universidad de São Paulo. Recuperado de https://teses.usp.br/teses/disponiveis/8/8145/tde-24032016-114502/es.php

Pasamonte, J. (2015). Vida y trabajos / Jerónimo de Pasamonte; edición de José Angel Sánchez Ibáñez y Alfonso Martín Jiménez. Alicante: Biblioteca Virtual Miguel de Cervantes. Recuperado de http://www.cervantesvirtual.com/o bra/vida-y-trabajos/

Pellicer, J. A. (s. f.).Vida de Miguel de Cervantes Saavedra. Recuperado de https://archive.org/stream/

Riquer, M. (2003). Para leer a Cervantes. Cervantes, Passamonte y Avellaneda. Barcelona: Acantilado. 
Rißler-Pipka, N. (2016). Avellaneda y los problemas de la identificación del autor. Propuestas para una investigación con nuevas herramientas digitales. Recuperado de https://opus.bibliothek.uni-augsburg.de/opus4/frontdoor/delive r/index/docId/3704/file/Mesa_Redonda_Neue_Folge_33.pdf

Rodríguez López-Vásquez, A. (2011a). El Quijote de Avellaneda: nuevos índices de atribución a José de Villaviciosa. Lemir, 15, 9-22.

Rodríguez López-Vásquez, A. (2011b). El Quijote de Avellaneda y José de Villaviciosa: algunas cuestiones de método y epistemológicas. Lemir, 15, 147-170.

Salas Barbadillo, A. J. (s. f.). La pereginación sabia. Recuperado de http://www.cervantesvirtual.com/obra-visor/la-pe regrinacion-sabia--0/html/fef925b8-82b1-11df-acc7-002185ce6064_1.html\#I_3_

Salas Barbadillo, A. J. (2008). La hija de la Celestina. (Enrique García Santo-Tomás, Ed.). Madrid: Cátedra.

Suárez Figaredo, E. (2004). Cervantes, Figueroa y el crimen de Avellaneda. Barcelona: Ediciones Carena.

Suárez Figaredo, E. (2009). ¿Cuándo se escribió el Quijote de Avellaneda? Revista Lemir, 13, 9-32.

Suárez de Figueroa, C. (2018). El pasajero. Recuperado de http://parnaseo.uv.es/lemir/Revista/Revista22/Textos/4 _El_Pasajero.pdf

Tubau, X. (2010). Temas e ideas de una obra perdida: la Spongia (1617) de Pedro de Torres Rámila. Revista de filología española, 90(2), 303-330.

Villalobos Lara, R. E. (2017). El Quijote en Chile. Primera edición y estudios bibliográficos desde 1863 a 1947. Santiago de Chile: RIL Editores.

Wickersham Crawford, J. P. (2005). Vida y obras de Cristóbal Suárez de Figueroa. Recuperado de https://users.pfw.e $\mathrm{du} /$ jehle/CERVANTE/othertxts/BiografiaFigueroa.PDF

\section{Notas}

1 La linealidad ideológica a que nos referimos es evidente, por ejemplo, en la elaboración de los diálogos. Al respecto vale consultar Martín Morán (2016). Para la cuestión de las implicaciones ideológicas sugerimos nuestro trabajo Intersticios ideológicos en los Quijotes de Cervantes, Avellaneda y Montalvo: un estudio comparativo sobre las representaciones sociales dominantes en las obras (O'Kuinghttons, 2015). Por otra parte, en su estudio sobre el Quijote en Chile, Villalobos (2017) ha reseñado cómo en la reescritura intervienen factores tanto de ideología y recepción como de intención creadora. Para otros alcances sobre el ejercicio de la imitación ver Ehrlicher (2016) y Hinrichs (2016).

2 Aun siendo un tema seductor, por razones de espacio y de objetivo no nos detendremos en la actualidad de los estudios generales sobre el enigma de Avellaneda. Para el interesado en conocer candidaturas de diverso calado recomendamos la espléndida panorámica que Gómez Canseco (Fernández de Avellaneda, 2014) aporta en su estudio introductorio a la edición conmemorativa del Quijote de Avellaneda.

3 Este último ha abierto el manejo de una cuantiosa base de datos almacenados en corpus que exponen de manera altamente operativa rasgos estilísticos sustentados en recurrencias lexicales y sintácticas. No obstante su promisora ventaja, RißlerPipka (2016) ha denunciado el riesgo de la manipulación de datos que comporta el recurso.

4 No obstante, si validamos que Avellaneda se reconoció a sí mismo en la obra y que en el acotado espacio literario otros también podrían haberlo hecho, el autor se pregunta “¿cómo es posible que no nos haya llegado nada de ello?” (Suárez Figaredo, 2004, p. 69).

5 Cree Suárez Figaredo que, habiendo sido Figueroa hombre de letras, pudo resentirse del discurso de las armas y letras contenido entre los capítulos XXXVII y XXXVIII de la primera parte. Pasajes como: "Quiténseme delante los que dijeren que las letras hacen ventaja a las armas, que les diré, y sean quienes se fuere, que no saben lo que dicen” (Cervantes, 2005, p. 320), pudieron actuar decididamente contra Cervantes. El mismo investigador sostiene: "Figueroa no era, en principio, una amenaza para los establecidos; pero con sus poco más de treinta años, sólida formación universitaria (doctor en Derecho Civil y Canónico), crítico, ambicioso y con excelente hoja de servicios en Italia, rabiaba por colocarse, y pudo cobrar particular aversión a quienes, peor preparados que él, le llevaban ventaja. Y Figueroa era de carácter sanguíneo y rencoroso" (Suárez Figaredo, 2004, p. 196).

6 Al respecto, el autor, habla del paquete que debió dejar Cervantes para Avellaneda bajo la forma de un inesperado pacto de contención. En otro orden, Pellicer lamenta la conducta de Figueroa hacia Cervantes, de quien se burló cuando a este le restaba muy poco de vida: "El doctor Suárez de Figueroa en un libro que imprimió el año siguiente desaprobó esta ocupación de Cervantes [haber redactado la dedicatoria de Trabajos de Persiles y Segismunda al conde de Lemos un día 
después de recibir la extrema unción] en ocasión tan funesta. 'Dura esta flaqueza en no pocos hasta la muerte, haciendo prólogos y dedicatorias hasta el punto de espirar”” (Pellicer, s. f., p. 200).

7 Suárez Figaredo admite el origen de la inquina de este modo: "Figueroa aspiró a ello [integrar el séquito de escritores que acompañaría al conde Lemos, nombrado virrey de Nápoles], y no sin méritos, pues, además de su gran formación, había vivido gran parte de su juventud en Italia (1588-1603/4), prestando servicios a su Rey” (2004, p. 200).

8 Conviene destacar que estas deducciones proceden de lecturas de un texto que no acostumbra ser explícito, y que por lo tanto reclama cautela a la hora de las acusaciones. De muestra consideremos el fragmento que insinúa las referidas comedias: "Acuérdome haber visto rondar a uno déstos (íbale a nombrar) la casa de cierto autor, de la forma que suele la de su dama el más enternecido galán. Fenecen en sus principios sus mayores osadías; porque apenas abre camino con la imaginación para entrar, cuando le cierra y detiene la falta de conocimiento, la estrañeza de la gente y la dificultad del motivo que le lleva. Duran estas irresoluciones tanto, que muchos, por falta de valedor, no hacen sino componer y echar comedias al suelo del arca, con el ansia que suele el avaro recoger y acumular doblones. Por esta causa se hallan infinitos con muchas gruesas represadas, esperando se representarán, cuando menos, en el teatro de Josafat, donde por ningún caso les faltarán oyentes" (Suárez de Figaredo, 2004, p. 103). Blanco de las diatribas de Figueroa contra la comedia eran las renovaciones introducidas por Lope de Vega, como la figuración de personajes reales o la indistinción entre trágico y cómico. Estas diatribas, apunta Espín, aun cuando fueron las más duras registradas en el siglo XVII, no tuvieron repercusión.

9 Considérense, por ejemplo, los rotundos términos con que lo tacha Menéndez Pelayo: "Quien busque... sátiras tan crueles como ingeniosas,... frases venenosas y felices..., lea El pasajero, en el cual... lo más interesante... es el carácter... del autor, público maldiciente, envidioso universal delos aplausos ajenos, tipo de misántropo y excéntrico que se destaca... del cuadro de la Literatura del s. XVII, tan alegre, tan confiada y tan simpática. ...una monstruosidad moral, de aquellas que ni el ingenio redime. Le tuvo, y grande, juntamente con una ciencia profunda de nuestra lengua, pero lo odioso de su condición y el mismo deseo de mostrarse solapado y agudo, con mengua de la claridad y del deleite, condenaron sus escritos al olvido, perdiendo él en honra propia lo que a tantos buenos había quitado" (Suárez Figaredo, 2004, p. 187).

10 Obra tenida como el mejor documento de la sociedad española de los inicios del siglo XVII.

11 Los encontramos en los siguientes segmentos: “¿Es posible pueda haber agradado a quien se mostró tan avieso, tan mal contentadizo, un borrón estéril, un bosquejo desnudo de todo el ornato con que le honráis?” (Suárez Figaredo, 2004, p. 118); "Nunca yo comunicara las obras del ingenio sino con adversarios, con mal contentadizos, ya que (según Plutarco), así como los amigos con adulación y blandas palabras nos dañan y trastornan, así, por opuesto, los enemigos con su enojo y rigor nos corrigen y enderezan" (Suárez Figaredo, 2004, pp. 183-184); "Tengo por cordura oír la comedia con atención, sin causar ruido ni estorbo. Son notados mucho allí los malcontentadizos y revoltosos, y se ponen en evidente riesgo de que el dueño de la farsa procure resentirse, apuntando en el teatro algunas faltas suyas, por donde vengan a ser conocidos y menospreciados en público" (Suárez Figaredo, 2004, p. 354).

12 Alarcón, recuerda Espín, respondió a esta cizaña en Dejar dicha por más dicha y Por mejoría mi casa dejaría, donde figura un escudero llamado Figueroa que lamenta la imposibilidad de usar su nombre en paz, como alusión al atribuido y correspondiente arribismo nobiliario de Figueroa. Para conocer otros alcances de su bilis contendora, sugerimos el estudio de Héctor Brioso Santos (2007) “Cristóbal Suárez de Figueroa: un enemigo de América y de los indianos en la España del siglo XVII”, donde se revisa la desaprobación del autor hacia la colonización de América y el temple de los indianos.

13 Muestra de estas colisiones es la referencia que Salas Barbadillo hace de él en su obra La peregrinación sabia, fábula en que los animales presiden una Academia literaria: “[...] el perro era un poeta muy envidioso, fisgaba siempre de los escritos ajenos y, como si fueran huesos, los roía y despedazaba; esta mala condición le granjeó muchos enemigos, que le llamaban por mal nombre el poeta Fisgarroa, compuesto de sus dos depravadas costumbres: fisgar y roer" (Salas Barbadillo, s. f., p. 72). Rodríguez López-Vásquez acude a este pasaje para precisar que, en la época, el verbo 'fisgar', que hoy equivale a 'escudriñar', era homólogo de 'burla aguda, satírica y maliciosa'. "Queda, pues, consagrado Cristóbal Suárez como el satírico mordaz y burlón de la Villa y Corte por medio de la modificación maliciosa de un apellido que, sin ser suyo, había adoptado literariamente", comenta el académico (Fernández de Avellaneda, 2011, pp. 31-32). A tenor de lo susodicho, Suárez Figaredo (2004) destaca la censura a la comercialidad que Figueroa vio en el teatro de Lope. La defensa que estampa en el prólogo de su Quijote, acota, pudo ser solo una excusa.

14 En su argumentación a favor de Villaviciosa, Rodríguez López-Vásquez refrenda la idea de que este no es un guiño sino una errata de la edición. Lo sugiere el elevado número de veces en que aparece la voz mil como sinónimo de muchos: “[...] el tiempo estancia y estudios de Villaviciosa en Alcalá de Henares explica su detallado conocimiento de la ciudad, pero explica también su conocimiento de aspectos de Cervantes que hacen innecesario recurrir a un escritor ofendido por Cervantes, a partir de una errata de imprenta evidente [...]” (2011a, p. 20).

15 En un más que excelente examen, Alfonso Martín Jiménez (2005) mantiene que el Quijote de Avellaneda circuló como manuscrito antes que publicado. El trabajo a que aludimos es Cervantes y Pasamonte. La réplica cervantina al Quijote de Avellaneda. 
16 El proceso fue gradual y se extendió hasta 1614.

17 Estos argumentos han sido relativizados y refutados por Enrique Suárez Figaredo. A modo de ejemplo, destaquemos el atribuido descuido de Espín al no advertir que la muerte de la sobrina del segundo Quijote se llama Madalena, y que la hermana menor de Cervantes se llamaba también Madalena, cuyo deceso ocurrió el 27 de enero de 1611. Este significativo dato lo ha llevado a afirmar: “[...] podría proponerse que Avellaneda no puso manos a la obra hasta después de enero de 1611, si aceptamos que lo del fallecimiento de "Madalena” no obedeció a la casualidad” (Suárez Figaredo, 2009, pp. 18-19). Por esta y otras simetrías, agrega el autor, cabe imaginar que Avellaneda buscó identificar a su exorbitado héroe con el propio Cervantes.

18 Sobre este problema conviene citar las conclusiones del autor en artículo publicado en la revista Lemir, número 13, de 2009: "Pretender establecer en qué estado se encontraría el manuscrito de Cervantes cuando cayó en sus manos el apócrifo sería tarea abrumadora - porque ha de descartarse una redacción lineal- y poco agradecida, pues el resultado siempre se prestará a la polémica. En mi opinión, y haciendo abstracción del orden final, cuando Cervantes redacta la primera estancia con los Duques ya ha leído a Avellaneda y se apresta a replicarle. Ahí se situaba la aventura de la resurrección de Altisidora, en la cual -al estilo de la aventura de la cueva de Montesinos- se descubría la existencia del Quijote apócrifo. Luego retocó por aquí y por allá lo ya escrito, unas veces copiando ideas de Avellaneda, otras desautorizándole, y en ocasiones para amenizar el relato con retazos de novelitas que dormían en los cajones de su bufete" (Suárez Figaredo, 2009, p. 26).

19 Este raciocinio sería tácito si se entendiera que el prólogo fue lo primero que se escribió. Sin embargo, importa recordar que en la época los exordios solían componerse cuando el resto del libro ya estaba cumplido. Siendo así, la mención a la novela de Salas debió ser una simple remisión, lo que la invalida como eje indiscutible de referencia temporal. Vale aprovechar la mención de este escritor para recordar que en 1940 Juan Bautista Sánchez Pérez trajo a la palestra el nombre de Salas como rival de Cervantes. Entre otros argumentos, buscó el socorro de los muy discutidos juegos de anagramas. Lo recuerda Figaredo en la coda de su introducción a La hija de La Celestina: “[...] frecuentó la casa de Cervantes, y convencido de que aun cuando éste tenía preparados algunos capítulos para la segunda parte de su historia de Don Quijote, no la publicaría [...], leyó el material compuesto y preparó la continuación [...] a imitación de la primera, durante los años 1610 y 1611, así como otros trabajos, entre ellos la novela La hija de Celestina, Los felices amantes, y El rico desesperado. A fines de 1611 [...] volvió a ser desterrado de Madrid, y salió para Burgos [...] pasando luego a Zaragoza, donde terminó el original [...] del Quijote, a la vez que La hija de Celestina [...] En Zaragoza se hizo, entre otros, amigo, si no lo era de antes, del alférez Francisco de Segura [...] El prólogo, dedicatoria y primer párrafo de este falso Quijote fueron escritos de mano de Francisco de Segura [...] y en el nombre Alisolán [...] bien indicó, como se lee a la primera mirada: Alonso Salas" (Salas Barbadillo, s. f., p. 3). Esta postulación, como ocurre con Vicente Espinel, encalla en un dato extra literario: las buenas relaciones que Salas Barbadillo mantuvo con Cervantes. Así lo apunta García SantoTomás en su introducción a la novela: "Cervantes le elogió en su Viaje del Parnaso-Salas firmó la censura de las Novelas ejemplares cervantinas el 31 de julio de 1613- y el madrileño le devolvió el elogio en numerosas ocasiones, incluyendo al propio Cervantes como co-narrador en El curioso, texto que insertó en El caballero puntual y que también incluyó un intercambio de misivas con el mismo Don Quijote" (Salas Barbadillo, 2008, p. 21). En la misma edición, y a modo de curiosidad, García Santo-Tomás informa que existe un libro llamado Avellaneda (publicado por Escelicer en 1940), cuyo autor, que firma J.B.S.P. sostiene que Avellaneda es Salas Barbadillo. El título, en verdad, es más extenso y lleva apariencia de índice: Avellaneda. I. Avellanedas. II. Contemporáneos de Avellaneda. III. Alonso Fernández de Avellaneda.

$20 \mathrm{Al}$ respecto, Suárez Figaredo razona: "Jerónimo de Pasamonte (cree Riquer) y también Vicente Espinel (creemos nosotros) aparecen caricaturizados en DQ-I en las figuras de un malhechor condenado a galeras y de un chulesco soldado, con los nombres de Ginés de Pasamonte (Cap. 23) y Vicente de la Rosa (Cap. 51), que resultan claros sinónomos voluntarios de sus nombres en la vida real. No creemos que aquí intervenga la casualidad" (2004, p. 152).

21 Prueba de esta solidaridad son los versos de La Galatea que aluden al poeta: "Del famoso Espinel cosas diría que exceden al humano entendimiento, de aquellas ciencias que en su pecho cría el divino de Febo sacro aliento. Mas, pues no puede de la lengua mía decir lo menos de lo más que siento, no diga más, sino que al cielo aspira, ore tome la pluma, ora la lira” (Cervantes, 1943, p. 712).

22 Según el autor, una de estas consecuencias es el riesgo de que la investigación científica decaiga a doxología. Para el conocimiento de la candidatura propuesta por Rodríguez recomendamos su estudio "El Quijote de Avellaneda y José de Villaviciosa: algunas cuestiones de método y epistemológicas” (Rodríguez López-Vásquez, 2011b).

23 Los requisitos que debiera cumplir el candidato a la autoría han ganado cierta estabilidad. Ello no quita que otros se vayan incorporando conforme el surgimiento de nuevas evidencias. Ponemos por caso lo expuesto por Martín Jiménez y Sánchez Ibáñez (Pasamonte, 2015) en su defensa de Jerónimo de Pasamonte. Basándose en el capítulo XXI, sostienen que Avellaneda sabía de la colegiata del Santo Sepulcro de Calatayud, posesión aragonesa de la Orden del Santo Sepulcro de Jerusalén. Quien postule un candidato, sostienen, deberá explicar por qué su autor está familiarizado con dicha cofradía. 
John O’Kuinghttons Rodríguez. Cristóbal Suárez de Figueroa, autor del segundo Quijote. Examen crít...

24 Iffland (1999) habla de la estructura ficcional del Quijote imitativo como una 'reorientación ideológica' del original cervantino. Esta premisa, creemos, puede implicar una considerable cuota de animadversión como justificación genética de la obra.

25 Véanse, por ejemplo, los datos que proporciona al respecto Tubau: "Para prestigiar la figura de Lope, su amigo escribe (entre 1618 y 1620) un diálogo titulado El Vega de la poética española. En este diálogo Elisio de Medinilla introducía un parlamento en el que se señalaba que la Poética de Aristóteles había sido la guía de Lope en todas sus composiciones. El diálogo se interrumpe lamentablemente (y quizá significativamente) cuando el propio Lope iba a dar cuenta de este particular. Elisio de Medinilla aquí está más cerca de Torres Rámila, de Suárez de Figueroa o de Cristóbal de Mesa que del propio Lope [...]” (Tubau, 2010, p. 330). 